\title{
Epidemiology and treatment of post-stroke depression
}

\author{
Stefano Paolucci \\ Fondazione Santa Lucia - I.R.C.C.S, \\ Rome, Italy
}

\begin{abstract}
Mood depression is a common and serious complication after stroke. According to epidemiological studies, nearly $30 \%$ of stroke patients develop depression, either in the early or in the late stages after stroke. Although depression may affect functional recovery and quality of life after stroke, such condition is often ignored. In fact, only a minority of patients is diagnosed and even fewer are treated in the common clinical practice. Moreover, the real benefits of antidepressant (AD) therapy in post-stroke depression have not been fully clarified. In fact, controlled studies on the effectiveness of ADs in post stroke depression (PSD) are relatively few. Today, data available suggest that ADs may be generally effective in improving mood, but guidelines for the optimal treatment and its length are still lacking.
\end{abstract}

Keywords: depression, stroke, antidepressant

The progressive decrease in stroke mortality observed in Western countries, in the last decades, and the subsequent increase of survivors with residual impairments and disabilities (Sarti et al 2000), have been accompanied by a growing interest in factors that could interfere with functional outcome and quality of life (QoL). In light of this, a crucial role is played by post-stroke depression (PSD).

In particular, mood depression is considered as the strongest predictor of QoL in stroke survivors (Kim et al 1999; King 1996). Moreover, PSD is associated with an increased disability ( Schwartz et al 1993; Herrmann et al 1998; Ramasubbu et al 1998; Kotila et al 1999; Pohjasvaara et al 2001), increased cognitive impairment (Kauhanen et al 1999), increased mortality, both on short and long term (Morris et al 1993; Schulz et al 2000; House et al 2001; Williams et al 2004), increase risk of falls (Jorgensen et al 2002) and, finally, with worse rehabilitation outcome (Sinyor et al 1986; Paolucci et al 1999, 2001; van de Weg et al 1999; Gillen et al 2001). Conversely, the absence of PSD in young adults is a significant predictor of the ability to return to work (Neau et al 1998). Moreover, an improvement of depressive symptoms has been associated with a better functional recovery (Chemerinski et al 2001).

In spite of the relative large number of papers available on PSD, it is surprising to note that the attention of authors has been focused on epidemiological features and impact of PSD both on functional outcome and QoL than on possible therapeutic approaches.

This review concerns a literature evaluation on epidemiological and therapeutic aspects of PSD. Relevant articles related to depression and cerebrovascular diseases selected from computer-based search have been examined using the Medline database from 1975 to August 2007.

\section{Epidemiological dimension and methodological problems}

Today, in spite of the abundant literature available on this topic, it is still difficult to define the real prevalence rate of PSD, essentially because of the weak concordance 
across studies. This relevant variability arises not only from methodological problems of the investigations (differences in study populations and the timing of assessments) but also from the complexity in recognition, assessment, and diagnosis of depression.

In fact, as shown in the Table 1, there is a large variability of diagnostic tools used for the detection of PSD. In fact, while most of the studies based the diagnosis on cutoff score in different rating scales, others followed a structured interview and the diagnostic standards defined by DSM (Diagnostic and statistical manual of mental disorders)-III, III-R, and IV, and some studies even based their assessment only on clinical findings.

Moreover, assessment of depression in stroke survivors may be often laborious and the risk of inappropriate diagnosis (under- or overdiagnosing) is high (Fedoroff et al 1991). In fact, PSD may not only be overdiagnosed because of somatic symptoms caused by medical illness, but also underdiagnosed, particularly in patients with cognitive impairment. Another problem, as observed by Schubert and coworkers (1992), may be the inadequacy of physicians without a proper psychiatric training (Schubert et al 1992). The correct attribution of somatic symptoms (psychomotor retardation, and disturbances in appetite, sleep, and sexual interest) to either PSD or stroke is a very relevant problem, because such symptoms may affect rating scales, as Hamilton Depression Rating Scale (HDRS), Montgomery Asberg Depression Rating Scale (MADRS), or Beck Depression Inventory (BDI), and also because they are among DSM criteria. It is important to remember that rating scales were designed to measure depression severity in primary depressive illness, rather than to diagnose depression, in particular for depression in comorbidity. Furthermore, DSM criteria for classification of disorders, (temporal criteria, in particular) are not always satisfied for dysthymia and major depression. So, we found cases diagnosed as major depression even in reports on PSD in settings characterized by short hospital stay, such as stroke units (Kellermann et al 1999; Berg et al 2001). Additionally, other relevant points, as evaluation-time after stroke (acute vs. chronic patients) and variability of the study setting (in-patients, outpatients, patients bedridden in rehabilitation structures, community), minimize the possibility of a generalization. Lastly, the problem of aphasia should be kept in mind. The exclusion of aphasic patients, because of the evident difficulty in evaluating depressive symptoms, reported in several of studies examined, may be an important confounding variable (Carson et al 2000). However, there is no concordance on frequency of PSD in aphasics, observed either in low (15\%)
(Damecour and Caplan 1991), in middle (24\%) (Laska et al 2007 ) and in high percentage ( $70 \%$ at 3 months and $62 \%$ at 12 months after stroke) of cases (Kauhanen et al 2000).

A recent meta-analysis, evaluating data from studies conducted between 1977 and 2002, estimated the pooled frequency at $33 \%$ (95\% confidence interval, $29 \%$ to $36 \%)$ (Hackett et al 2005b), even if with relevant differences across studies. In particular, the pooled estimate from the population-based studies was equal in the acute and medium-term phases (33\%), with a slight increase to $34 \%$ in the long-term phase of recovery after stroke. Moreover, there were only slight differences in the pooled frequencies in the hospital-based (acute 36\%, medium-term 32\%, and long-term 34\%) and rehabilitation-based studies (acute 30\%, medium 36\%, and long-term 34\%) over time.

Studies available after the publication of that report confirmed that PSD is generally observed in nearly one third of cases (Vataja et al 2004; Verdelho et al 2004; Paolucci et al 2006; Linden et al 2007; Townend et al 2007). However, a certain degree of variability in the percentages was observed in those reports, too. In particular, the percentage of depression observed in the Sidney Stroke Study was lower than in the previous ones (Brodaty et al 2007). Moreover, recent longitudinal studies observed not only that frequency PSD increases in prevalence over the initial weeks post-stroke, in particular within three months from stroke, despite an improvement in disability (Andersen et al 1994b; Aben et al 2003; Paolucci et al 2006), but also that patients with early onset PSD were not necessarily affected later and vice versa, indicating the dynamic nature of PSD in the early stages.

Only few epidemiological data on vascular depression are available today. Vascular depression is a new diagnostic concept based on hypothesis that chronic ischemic damage is an important cause of depression in the elderly. This concept initially emerged from the finding that patients with late-onset depression had higher rate of encephalomalacia or hyperintensities observed with magnetic resonance imaging (MRI) compared with patients with early-onset depression (Hickie et al 1995), and was later formulated by Alexopoulos and coworkers in 1997. These authors hypothesized that cerebrovascular disease can predispose, precipitate, or perpetuate a depressive syndrome in older adults (Alexopoulos et al 1997a). Affected individuals display more apathy, retardation, and lack of insight, and less agitation and guilt than do elderly individuals who are depressed without vascular risk factors, on one hand, and also greater disability and cognitive impairment, on the other (Alexopoulos et al 1997b). Mast and coworkers 
Table I Prevalence of PSD according to time and setting of evaluation

\begin{tabular}{|c|c|c|c|c|c|c|}
\hline Authors & $\mathbf{n}$ & Population & Country & Time & Criteria & $\%$ \\
\hline Folstein et al 1977 & 20 & Rehab hosp & USA & $\mathrm{Im}$ & HDRS/PSE & 45 \\
\hline Robinson et al 198I & 18 & hospital-based & USA & $<\mathrm{I} \mathrm{m}$ & HDRS, ZSRDS & 61 \\
\hline Feibel et al 1982 & 91 & outpatient & USA & $6 \mathrm{~m}$ & Nursing evaluation & 26 \\
\hline Robinson et al 1983 & 103 & hospital-based & USA & $\mathrm{I} \mathrm{m}$ & HDRS, PSE,DSM-III & 47 \\
\hline Sinyor et al 1986 & 64 & Rehab hosp & CND & $<2 \mathrm{~m}$ & ZSRDS & 47 \\
\hline Ebrahim et al 1987 & 149 & hospital-based & UK & $6 \mathrm{~m}$ & GHQ & 23 \\
\hline \multirow[t]{3}{*}{ Wade et al 1987} & 379 & Community & UK & $<\mathrm{Im}$ & WDI & 22 \\
\hline & 377 & & & $6 \mathrm{~m}$ & & 20 \\
\hline & 348 & & & $12 \mathrm{~m}$ & & 18 \\
\hline Eastwood et al 1989 & 87 & Rehab hosp & CND & $21 \mathrm{~d}-6 \mathrm{~m}$ & HDRS, GDS & 50 \\
\hline Finset et al 1989 & 42 & Rehab hosp & Norway & $6 \mathrm{~m}$ & GCRD & 36 \\
\hline Malec et al 1990 & 20 & Rehab hosp & USA & $\mathrm{I} \mathrm{m}$ & HDRS & 35 \\
\hline \multirow[t]{2}{*}{ Morris et al 1990} & 99 & rehab hosp & $\mathrm{AU}$ & $2 \mathrm{~m}$ & MADRS/CIDI & 35 \\
\hline & 56 & & & $15 \mathrm{~m}$ & & 12 \\
\hline \multirow[t]{2}{*}{ Parikh et al 1990} & 63 & hospital-based & USA & $<\mathrm{Im}$ & HDRS, PSE,DSM-III & 39 \\
\hline & & hospital-based & & $2 y$ & & 39 \\
\hline Fedoroff et al 1991 & 205 & hospital-based & USA & $<\mathrm{Im}$ & HDRS, PSE,DSM-III & 41 \\
\hline \multirow[t]{3}{*}{ House et al I99| } & 89 & community & UK & $\mathrm{I} \mathrm{m}$ & PSE, DSM-III & 23 \\
\hline & 119 & & & $6 \mathrm{~m}$ & & 20 \\
\hline & 112 & & & $12 \mathrm{~m}$ & & 16 \\
\hline Schubert et al 1992 & 18 & rehab hosp & USA & $1.5 \mathrm{~m}$ & BDI, DSM-III & 72 \\
\hline \multirow[t]{5}{*}{ Astrom et al 1993} & 80 & hospital-based & SW & $2 \mathrm{~m}$ & DSM-III & 25 \\
\hline & 77 & & & $3 \mathrm{~m}$ & & 31 \\
\hline & 73 & & & Iy & & 16 \\
\hline & 57 & & & $2 y$ & & 19 \\
\hline & 49 & & & $3 y$ & & 29 \\
\hline Schwartz et al 1993 & 91 & rehab hosp & USA & $7 \mathrm{~m}$ & DSM-III & 40 \\
\hline \multirow[t]{2}{*}{ Andersen et al 1994} & 285 & hospital-based & DK & $\mathrm{I} \mathrm{m}$ & HDRS & 21 \\
\hline & 285 & & & Iy & & 41 \\
\hline Burvill et al 1995 & 294 & community & $\mathrm{AU}$ & $4 \mathrm{~m}$ & PSE, DSM-III & 23 \\
\hline Diamond et al 1995 & 14 & rehab hosp & USA & & GDS & 36 \\
\hline Gonzalez-Torrecillas et al 1995 & 130 & rehab hosp & Belgium & $\mathrm{I} \mathrm{m}$ & HDRS, MADRS & 37 \\
\hline Wilkinson et al 1997 & 96 & community & UK & $5 y$ & HADS & 36 \\
\hline $\mathrm{Ng}$ et al 1995 & 52 & rehab hosp & Singapore & $<\mathrm{I} \mathrm{m}$ & DSM-III-R & 55 \\
\hline \multirow[t]{2}{*}{ Herrmann et al 1998} & 150 & hospital-based & CND & $3 \mathrm{~m}$ & MADRS & 27 \\
\hline & 133 & & & Iy & & 22 \\
\hline \multirow[t]{2}{*}{ Pohjasvaara et al 1998} & 277 & hospital-based & FIN & $3 \mathrm{~m}$ & DSM-III-R & 40 \\
\hline & 276 & & & $15 \mathrm{~m}$ & & 45 \\
\hline Neau et al 1998 & 71 & outpatient & & $>1 y$ & MADRS/DSM-III & 48 \\
\hline \multirow[t]{2}{*}{ Kotila et al 1999} & 321 & community & FIN & $3 \mathrm{~m}$ & $\mathrm{BDI}$ & 47 \\
\hline & 311 & & & $12 \mathrm{~m}$ & & 47 \\
\hline Kellermann et al 1999 & 82 & hospital-based & Hungary & I w & $\mathrm{BDI}$ & 15 \\
\hline \multirow{2}{*}{ Gainotti et al 1999} & 153 & rehab hosp & Italy & $2 \mathrm{~m}$ & HDRS & 32 \\
\hline & 153 & & & $4 \mathrm{~m}$ & & 60 \\
\hline Kauhanen et al 1999 & 106 & rehab hosp & FIN & $3 \mathrm{~m}$ & PSE, DSM-IIII-R & 53 \\
\hline Paolucci et al 1999 & 470 & rehab hosp & Italy & $1.5 \mathrm{~m}$ & HDRS & 27 \\
\hline van de Weg et al 1999 & 85 & rehab hosp & Netherlands & $20-40 \mathrm{~d}$ & DSM-III-R & 35 \\
\hline Berg et al 200I & 89 & hospital-based & FIN & $<\mathrm{Im}$ & $\mathrm{BDI}$ & 27 \\
\hline Gillen et al 200I & 243 & rehab hosp & USA & $<\mathrm{I} \mathrm{m}$ & GDS & 13 \\
\hline Vataja et al $200 \mathrm{I}$ & 275 & outpatient & FIN & $3 \mathrm{~m}$ & PSE, DSM-IIII-R & 40 \\
\hline Tang et al 2002 & 157 & rehab hosp & China & $\mathrm{I} \mathrm{m}$ & DSM-III-R & 17 \\
\hline \multirow[t]{2}{*}{ Aben et al 2002} & 154 & hospital-based & Netherlands & $\mathrm{I} \mathrm{m}$ & DSM-IV & 22 \\
\hline & 154 & & & $2 y$ & DSM-IV & 39 \\
\hline Eriksson et al 2004 & 15747 & community & Sweden & $3 \mathrm{~m}$ & Self reported & 1 \\
\hline Cassidy et al 2004 & 50 & rehab hosp & Ireland & $6 \mathrm{~m}$ & DSM-IV, HDRS & 20 \\
\hline Mast et al 2004 & 195 & rehab hosp & USA & $<\mathrm{Im}$ & DSM-III-R & 36 \\
\hline Verdelho et al 2004 & 110 & outpatient & France & $6 \mathrm{~m}$ & MADRS & 43 \\
\hline
\end{tabular}

(Continued) 
Table I (Continued)

\begin{tabular}{|c|c|c|c|c|c|c|}
\hline & 96 & & & Iy & & 36 \\
\hline & 71 & & & $2 y$ & & 24 \\
\hline & 73 & & & $3 y$ & & 18 \\
\hline Vataja et al 2004 & 70 & outpatient & FIN & $3 \mathrm{~m}$ & PSE, DSM-IIII-R & 37 \\
\hline Naess et al 2005 & 196 & outpatient & Norway & $6 y$ & MADRS & 29 \\
\hline Paul et al 2006 & 441 & outpatient & Australia & $5 y$ & IDAS & 17 \\
\hline Hackett et al 2006 & 739 & community & NZ & $6 \mathrm{~m}$ & $\mathrm{GHQ}$ & 27 \\
\hline Jia et al 2006 & 5825 & $\begin{array}{l}\text { hospital-based, } \\
\text { retrospective }\end{array}$ & USA & Iy & clinical & 41 \\
\hline \multirow[t]{2}{*}{ Paolucci et al 2006} & 1064 & hospital-based & Italy & $\mathrm{Im}$ & BDI, DSM-IV & 22 \\
\hline & 821 & & & $9 \mathrm{~m}$ & & 36 \\
\hline \multirow[t]{2}{*}{ Townend et al 2007} & 125 & hospital-based & Australia & $\mathrm{I} \mathrm{m}$ & HADS & 16 \\
\hline & 125 & & & $3 \mathrm{~m}$ & HADS & 21 \\
\hline van de Port et al 2007 & 165 & outpatient & Netherlands & $3 y$ & CES-D & 19 \\
\hline Linden et al 2007 & 149 & outpatient & Sweden & $20 \mathrm{~m}$ & DSM-III-R & 34 \\
\hline \multirow[t]{2}{*}{ Brodaty et al 2007} & 164 & hospital-based & Australia & $3 \mathrm{~m}$ & DSM-III-R & 12 \\
\hline & 164 & outpatient & Australia & $15 \mathrm{~d}$ & DSM-IV & 21 \\
\hline
\end{tabular}

Abbreviations: d, days; m, months; y, years; BDI, Beck Depression Inventory; CES-D, Centre for Epidemiologic Studies Depression Scale; CIDI, Composite International Diagnostic Interview; DSM, Diagnostic and Statistical Manual of Mental Disorder; GCRD, Global Clinical Rating of Depressed mood; GDS, Geriatric Depression Scale; GHQ, General Health Questionnaire; HADS, Hospital Anxiety and Depression Scale; HDRS, Hamilton Depression Rating Scale; MADRS, Montgomery Asberg Depression Rating Scale; IDAS, Irritability, Depression and Anxiety Scale; PSE, Present State Examination;WDI,Wakefield Depression inventory; ZSRDS, Zung Self Rating Depression Scale.

reported vascular depression in nearly $35 \%(35.2 \%)$ of patients with cerebrovascular risk factors admitted in geriatric rehabilitation, but without clinical evidence of stroke (Mast et al 2004). In that study, a positive association was established between depression and increasing percentage of cerebrovascular risk factors (Mast et al 2004). Furthermore, patients with depression and subcortical vascular lesions have poor response to antidepressants (Simpson et al 1998), while might be effective dopamine acting agents or norepinephrine enhancing agents (Alexopoulos 2006). Thus, should vascular depression be recognized as a separate psychiatric disorder or as a diagnostic subtype of major depressive disorder? Indeed, Alexopoulos refined the notion of vascular depression, proposing a depression executive dysfunction (DED) disorder of late-life, but only on the basis of clinical criteria and regardless the etiology (Alexopoulos 2001), while Taylor and coworkers (2006) proposed subcortical ischemic depression as specific entity. On the other hand, while the former may be caused by vascular disease, the latter requires a subcortical vascular impairment. Further researches are needed to clarify these and other doubts.

\section{Treatment studies}

Although antidepressant (AD) drugs have been discovered many decades ago [monoamine oxidase inhibitors (MAOIs) in the 1950s, tricyclic antidepressant (TCA) imipramine in 1957 and first selective serotonin reuptake inhibitor (SSRI), fluoxetine in 1988], most patients today do not receive an effective specific treatment. The attitude that PSD is a natural and inevitable condition which is not important to treat seems still common. General opinion appears to be that depression improves if the patient's physical condition improves (Gustafson et al 1995). Moreover, physicians are often reluctant to prescribe ADs to older patients with relevant physical illnesses (House et al 1989), because of the perceived risk of side effects especially on the cardiovascular system, fear of drug interactions in multiple comorbidity, and poor experience of depression treatment in the elderly. However, a recent systematic review of 18 randomized controlled trials comparing any $\mathrm{AD}$ drug with placebo or no treatment in depressed adults with a specified physical disorder showed that ADs cause improvement in depressive symptoms in patients with a wide range of physical diseases (Gill and Hatcher 1999). In spite of these data, not only the studies on therapeutic approaches on PSD are relatively scarce, but also most of studies reported the effects of AD drugs only on mood disturbance. In fact, even if some authors suggested the favorable effect of AD drugs on functional recovery (Fedoroff and Robinson 1989), there are only few studies that evaluated the impact of ADs on functional outcome and rehabilitation results (Reding et al 1986; Fedoroff and Robinson 1989; GonzalezTorrecillas et al 1995; Dam et al 1996; Miyai and Reding 1998; Paolucci et al 1999; Gainotti et al 2001; Paolucci et al 2001).

Table 2 reports the percentages of patients treated with ADs in papers regarding prevalence and clinical impact of PSD. 
Table 2 Percentages of patients treated with antidepressant in studies on prevalence of PSD

\begin{tabular}{|c|c|c|c|c|}
\hline Authors & $\mathbf{n}$ & Population & Country & $\begin{array}{l}\% \text { patients } \\
\text { treated }\end{array}$ \\
\hline Sinyor et al 1986 & 64 & Rehab hosp & CND & 33 \\
\hline Ebrahim et al 1987 & 149 & hospital-based & UK & 15 \\
\hline Parikh et al 1990 & 63 & hospital-based & USA & 8 \\
\hline Herrmann et al 1998 & 150 & hospital-based & Canada & 19 \\
\hline Pohjasvaara et al 1998 & 277 & hospital-based & FIN & 39 \\
\hline Kotila et al 1999 & 321 & community & FIN & 17 \\
\hline Kauhanen et al 1999 & 106 & rehab hosp & FIN & 36 \\
\hline Paolucci et al 1999 & 470 & rehab hosp & Italy & 100 \\
\hline van de Weg et al 1999 & 85 & rehab hosp & Netherlands & 20 \\
\hline Eriksson et al 2004 & 15747 & community & Sweden & 49 \\
\hline Cassidy et al 2004 & 50 & rehab hosp & Ireland & 60 \\
\hline Paul et al 2006 & 441 & outpatient & Australia & 22 \\
\hline Paolucci et al 2006 & 1064 & hospital-based & Italy & 49 \\
\hline Jia et al 2006 & 5825 & $\begin{array}{l}\text { hospital-based, } \\
\text { retrospective }\end{array}$ & USA & 63 \\
\hline
\end{tabular}

\section{The choice of optimal treatment}

There is relatively little comparative information on how to make the choice of one AD over another, and none at all specific to PSD. Today, SSRIs are the recommended pharmacotherapy of PSD for their favorable tolerability profile (Turner-Stokes and Hassan 2002; SPREAD 2005). In fact, the affinity of TCAs for a number of central receptors including muscarinic cholinergic and histaminergic receptors makes them not recommended as first-line choice for treatment of PSD. Conversely, SSRIs have no affinity for cholinergic or histaminergic receptors and thus are generally well tolerated, and do not have cardiovascular or sedative effects. However, the SSRIs are not entirely without side-effects. Gastrointestinal symptoms, headache, sexual dysfunction and insomnia are relatively common. Arguably, the most important difference between the SSRIs lays in their potential to cause drug- drug interactions through inhibition of cytochrome-P450 isoforms, which is different for each SSRI. Thus, fluvoxamine is a potent CYP1A2 and CYP2C19 inhibitor, and a moderate CYP2C9, CYP2D6, and CYP3A4 inhibitor; fluoxetine and paroxetine are potent CYP2D6 inhibitors; sertraline is a moderate CYP2D6 inhibitor; and citalopram has little effect on the major cytochrome-P450 isoforms (Hemeryck and Belpaire 2002). So, fluvoxamine (CYP1A2 inhibitor) can cause an increase of blood levels of theophyllin or caffeine, while paroxetine and fluoxetine (CYP2D6 inhibitors) an increase of concentration of TCAs or atypical antipsychotics. Knowledge of the CYP-isoforms involved in the metabolism of the co-administered drug may help clinicians to predict and avoid potentially dangerous drug- drug interactions. Expected interactions can usually be managed by appropriate dose adjustments and titration of the drug. Importantly, the use of SSRIs has been associated with increased risk of bleeding complications (Skop and Brown 1996), possibly as a result of inhibition of platelet aggregation (Maurer-Spurej et al 2004). However, in a recent systematic review, Ramasubbu and colleagues (2004) observed that SSRI treatment had a very low rate of cerebrovascular adverse reactions. In particular, two case-control studies mentioned in that review showed no association between SSRI use and intracranial hemorrhage (de Abajo et al 2000; Bak et al 2002).

\section{Nonpharmacological management}

Today, the main therapeutic approach of PSD, and in particularly in subacute phase after stroke, is essentially pharmacological. In fact, a psychotherapeutic intervention is not only expensive in terms of staff time and expertise, but also requires several weeks before showing any clinical improvement. This delay may be critical for the outcome in a time-limited course of rehabilitation. Therefore, in the common clinical practice, $\mathrm{AD}$ treatment is the most realistic solution, with psychotherapeutic intervention reserved for those in whom ADs are either inappropriate or not tolerated. Regarding the effectiveness of psychotherapeutic interventions, methodological limitations in existing research prevent a conclusion as any psychological intervention has empirical support for its effectiveness (Gordon and Hibbard 1997; Kneebone and Dunmore 2000). On the other hand, cognitive behavioral therapy has shown some promising results that make it worthy of further exploration (Lincoln et al 1997; Lincoln and Flannaghan 2003). 
Table 3 Controlled studies on treatment of post-stroke depression

\begin{tabular}{|c|c|c|c|c|c|c|c|}
\hline Authors & No & Treatment studied & Design & $\begin{array}{l}\text { Time } \\
\text { from } \\
\text { stroke }\end{array}$ & $\begin{array}{l}\text { Trial } \\
\text { length }\end{array}$ & $\begin{array}{l}\text { Outcome } \\
\text { measures }\end{array}$ & Results \\
\hline Lipsey et al I984 & 34 & nortryptiline vs placebo & DB & $\leq 18 \mathrm{~m}$ & $4-6 w$ & HDRS, ZSRDS & $\begin{array}{l}\text { nortriptyline more effective than placebo in } \\
\text { reduction of depression }\end{array}$ \\
\hline Reding et al 1986 & 27 & trazodone vs placebo & DB & $6 w$ & $\sim 4-5 w$ & ZSRDS & trazodone trend towards better functional status \\
\hline Andersen et al 1994 & 66 & citalopram vs placebo & DB & $2-52 w$ & $16 w$ & HDRS & $\begin{array}{l}\text { citalopram more effective than placebo in reduc- } \\
\text { tion of depression }\end{array}$ \\
\hline Lauritzen et al 1994 & 20 & $\begin{array}{l}\text { Imipramine+mianserin vs } \\
\text { desipramine+mianserin }\end{array}$ & DB & $<3 \mathrm{~m}$ & $6 w$ & HDRS & $\begin{array}{l}\text { Imipramine }+ \text { mianserin more effective than } \\
\text { desipramine }+ \text { mianserin in reduction of depres- } \\
\text { sion }\end{array}$ \\
\hline Robinson et al 2000 & 56 & $\begin{array}{l}\text { nortryptiline vs fluoxetine } \\
\text { vs placebo }\end{array}$ & DB & $4-16 w$ & $12 w$ & HDRS & $\begin{array}{l}\text { nortriptyline produced a significantly higher } \\
\text { response rate than fluoxetine or placebo }\end{array}$ \\
\hline Wiart et al 2000 & 31 & fluoxetine vs placebo & DB & $<3 \mathrm{~m}$ & $6 w$ & MADRS & $\begin{array}{l}\text { fluoxetine more effective than placebo in reduc- } \\
\text { tion of depression }\end{array}$ \\
\hline Fruehwald et al 2003 & 54 & fluoxetine vs placebo & DB & $<2 w$ & $3 \mathrm{~m}$ & HDRS, BDI & $\begin{array}{l}\text { fluoxetine more effective than placebo at } \\
\text { I8-month follow-up evaluation }\end{array}$ \\
\hline Rampello et al 2004 & 74 & citalopram vs reboxetina & DB & $<12 \mathrm{~m}$ & $16 w$ & HDRS, BDI & $\begin{array}{l}\text { citalopram better in anxious depressed patients, } \\
\text { reboxetine more effective in retarded depressed } \\
\text { patients. }\end{array}$ \\
\hline Murray et al 2005 & 123 & sertraline vs placebo & DB & $3 d-1 y$ & $26 w$ & MADRS, EDS & $\begin{array}{l}\text { sertraline superior only in emotional distress, } \\
\text { emotionalism and QoL }\end{array}$ \\
\hline Choi-Kwon et al 2006 & 152 & fluoxetine vs placebo & DB & $14 \mathrm{~m}$ & $3 \mathrm{~m}$ & $\begin{array}{l}\text { BDI, clinical, } \\
\text { STAS }\end{array}$ & $\begin{array}{l}\text { fluoxetine more efficacious only in the treatment } \\
\text { of emotional incontinence and anger proneness. }\end{array}$ \\
\hline
\end{tabular}

Abbreviations: w, weeks; m, months; y, years; DB, double-blind; BDI, Beck Depression Inventory; HDRS, Hamilton Depression Rating Scale; MADRS, Montgomery Asberg Depression Rating Scale; QoL, Quality of Life; STAS, Spielberger Trait Anger Scale.

\section{Controlled pharmacological studies}

Controlled studies on the effectiveness of ADs in PSD are relatively few, and they are essentially related to the use of TCAs or SSRIs (Table 3). Data on usefulness of new dualcomponent ADs are still not available, to our knowledge.

In a recent Cochrane review, only 7 trials with $\mathrm{AD}$, with a total of 615 patients, entered the meta-analyses (Hackett et al 2004, 2005a). The results of meta-analyses showed that there was evidence of a improvement in depression rating scales, but not in terms of a complete remission of depression following stroke (Hackett et al 2004, 2005a). However, some methodological aspects of this review have been criticized. In particular, Chen and Guo (2006) suggested that the overall effects of $\mathrm{AD}$ treatment in term of various depression scores would better be estimated by separating the pretreatment and post-treatment instead of calculating the mean differences. In this fashion, $\mathrm{AD}$ treatments were effective in patients after the stroke in term of reducing the symptoms of depression. Moreover, can the concept of remission be applied in patients with depression in comorbidity? In fact, the idea of remission refers to a return to symptom-free state or premorbid levels of functioning (Bakish 2001). Such a model for depression in comorbidity is obviously arduous to obtain, because of the presence of somatic symptoms.

In another recent review, involving six pharmacological studies, there was evidence that ADs significantly improved mood, also in spite of a relevant number of dropouts due to side effects treatment, especially with heterocyclic ADs (Bhogal et al 2005). So, it appears that both TCAs and SSRIs may be effective in the treatment of PSD, although the latter may produce fewer side-effects.

Two randomized, double-blinded, placebo-controlled studies have evaluated the effectiveness of nortriptyline, a tricyclic drug (Lipsey and Robinson 1984; Robinson et al 2000). In the last one, the effectiveness of fluoxetine was also assessed (Robinson et al 2000). In both studies, a significant improvement in depression symptoms was observed in the treated groups as compared to controls. In particular, in 
the first study a mean baseline to endpoint improvement in HDRS score of $79 \%$ was observed in patients treated with nortriptyline as compared with an improvement of $40 \%$ in patients treated with placebo (Lipsey and Robinson 1984). In the second study, the mean improvement in HDRS score was higher in depressed patients treated with nortriptyline (60\% vs. $9 \%$ for patients treated with fluoxetine and $30 \%$ with placebo) (Robinson et al 2000). Furthermore, in the study by Robinson and colleagues (2000), but not in that by Lipsey and Robinson (1984), a better recovery in activities of daily living for nortriptyline group was observed. However, there was disagreement regarding drop-out rate: higher among those treated with nortriptyline (38\%) in the study by Lipsey and Robinson (1984), and among those treated with fluoxetine (40\%) in the study by Robinson and colleagues (2000). However, in this latter study, such high drop-outs rate with fluoxetine might have been due to the relative high dose (up to $40 \mathrm{mg}$ per day) of fluoxetine used (Robinson et al 2000). Moreover, the results of this study fostered the discussion about methodological problems (Van de et al 2003).

Two double-blinded controlled studies have assessed the effectiveness of citalopram, a selective serotonin reuptake inhibitors (SSRI), the first one vs. placebo and the second one vs. noradrenergic drug reboxetine (Andersen et al 1994a; Rampello et al 2004). In both studies, citalopram showed good efficacy and tolerability. In the first study, a mean baseline to endpoint improvement in HDRS score of $45.5 \%$ was observed in patients treated with citalopram as compared with an improvement of $16 \%$ in patients treated with placebo. Although the drop-out rate was higher in citalopram group, the reported side effects were relatively well tolerated and transient (Andersen et al 1994a). In the second trial, Rampello et al showed that citalopram exhibited greater efficacy in anxious depressed patients, while reboxetine was more effective in retarded depressed patients. No severe side effects were recorded during the study. The drop-out rate was similar between groups, too (three for both treatment) (Rampello et al 2004).

Four studies evaluated the effectives of fluoxetine, another SSRI agent, both on early and late phase after stroke (Robinson et al 2000; Wiart et al 2000; Fruehwald et al 2003; Choi-Kwon et al 2006). The results of these studies are conflicting. In particular, while a positive action on mood even in early phase was observed by Wiart and colleagues (2000), with a mean improvement in MADRS score of 58\% for fluoxetine group vs. $31 \%$ in placebo group, Fruehwald and coworkers (2003) observed such positive action only in the follow-up. Moreover, Choi-Kwon and colleagues (2006) found that fluoxetine was effective only on emotional incontinence and anger proneness, while Robinson and coworkers (2000) above described a lower effectiveness in comparison with nortriptyline. The drop-out rates were also conflicting: Fruehwald observed no drop-outs during the treatment, Wiart only two $(13.3 \%)$ in patients treated with fluoxetine, while Choi-Kwon $19.7 \%$ in fluoxetine group and $15.8 \%$ in placebo group (Wiart et al 2000; Fruehwald et al 2003; Choi-Kwon et al 2006).

Sertraline, another SSRI AD, showed no advantage in comparison to placebo either on major depressive episode or minor depressive disorder (Murray et al 2005). In fact, both groups improved substantially, with no differences between the treatments, either for major depressive episode or minor depressive disorder, or for short- or long-term antidepressant effect and neurologic outcome. However, the compound showed a significantly positive effect only on QoL at follow-up at week 26. No serious side effects were observed (Murray et al 2005).

A study by Lauritzen and coworkers (1994) compared the efficacy of two TCAs, desipramine against imipramine, both drugs combined with mianserin. The doses of the drugs were flexible, with side-effects as a guide during treatment. Imipramine treatment was more effective than desipramine in reducing depressive symptoms evaluated by means of Melancholia Scale, but not by means of HDRS. However, a large proportion (35\%) of the sample was lost in the follow-up, particularly in the desipramine group (Lauritzen et al 1994).

Lastly, Reding and colleagues (1986) evaluated the response of depressive symptoms to trazodone in a controlled trial vs. placebo. They showed that trazodone treated patients had a tendency to increase in autonomy in ADL measured by the Barthel index compared to patients treated with placebo. However, a high drop-out rate due to side effects was observed in both groups of patients. In particular, twelve patients discontinued the study: six patients from the trazodone group (4 sedation, 1 eye discomfort, 1 refusal), but also six patients in placebo group (4 sedation, 1 nausea, 1 dizziness). Moreover, because of the particular study design, it was not possible to compare the improvement in depression scores of both groups.

\section{Other studies}

There are other studies that evaluated the impact of different type of ADs on functional outcome and rehabilitation results. Today, AD therapy may be beneficial to functional recovery but it cannot abolish the detrimental effect of depression on functional outcome (Gonzalez-Torrecillas et al 1995; Dam et al 1996; Miyai and Reding 1998; Gainotti et al 2001). 
In a nonrandomized study published in 1995, GonzalezTorrecillas and colleagues showed that treated PSD patients (with nortriptyline or fluoxetine) had not only a better mood, but also a better functional and cognitive outcome compared to untreated PSD patients. Moreover, the study was nonblinded: fluoxetine was given to patients with cardiac defects and nortriptyline to those without. Both drugs made similar gains in both mood and functional ability (GonzalezTorrecillas et al 1995).

Some years later Gainotti and colleagues (2001) confirmed that functional recovery of nontreated depressed patients was poorer than the nondepressed and the depressed but treated patients.

Dam and colleagues (1996) observed that patients treated with fluoxetine had better rehabilitation results in comparison with those of patients treated with norepinephrine reuptake blocker maprotiline or placebo. These effects were not related to the specific antidepressant action. Moreover, both groups treated with Ads showed a significant baseline to endpoint mean improvement in HDRS score (fluoxetine $30 \%$, maprotiline 18\%). Mean improvement in placebo group was $12 \%$.

This favorable role of fluoxetine on functional status was confirmed also by another study, in which patients treated with fluoxetine or trazodone showed a better improvement on functional independence measure compared with patients treated with desipramine (Miyai and Reding 1998).

Since serotonin (5-HT) stimulates motor function, there are some studies that investigated the hypothesis that a pharmacological potentiation of 5-HT neurotransmission may improve motor function in healthy subjects and recovery in poststroke patients (Pariente et al 2001; Loubinoux et al 2002). In particular, in a double-blind, crossover, placebocontrolled study on 8 patients with pure motor hemiparesis, a single dose of fluoxetine was able to significantly improve motor skills of the affected side (Pariente et al 2001). However, other experimental reports (after focal ischemia in rats) did not confirm these adjuvant action of fluoxetine on recovery of motor function (Windle and Corbett. 2005).

ADs may reduce post stroke mortality. In a 9 year followup study, treatment with fluoxetine or nortriptyline for 12 weeks during the first 6 months after stroke significantly increased the survival of both depressed and nondepressed patients (Jorge et al 2003).

Lastly, there are few studies on the usefulness of new dual-agents SNRIs (serotonin and norepinephrine reuptake inhibitors), as venlafaxine or milnacipran and duloxetine (Dahmen et al 1999; Yamakawa et al 2005), but methodological problems (open-label studies and with small case-series) reduce the power of these data.

\section{Prevention of PSD}

A recent Cochrane review, evaluating data from nine trials (11 comparisons) involving different pharmaceutical agents, and three trials of psychotherapy, found no clear effect of either pharmacotherapy or psychotherapy on the prevention of depressive illness or disability (Anderson et al 2004). Moreover, data from a more recent trial showed that sertraline treatment, $50 \mathrm{mg} /$ day, had no advantage in comparison to placebo in preventing PSD (Almeida et al 2006).

A more recent meta-analysis published in 2007, evaluating 10 randomized clinical trials, with a total of 703 nondepressed stroke patients, found that ADs prophylaxis was associated with a significant reduction in the occurrence rate of newly developed poststroke depression (12.54\% in the treated group vs $29.17 \%$ in control group) (Chen et al 2007).

\section{Length of treatment}

At present, there is no scientific evidence regarding the optimal length of treatment of PSD. Many of the available trials terminate at six weeks, but withdrawal at this stage may result in relapse. In a recent review, Turner-Stokes and Hassan (2002) recommended carrying on AD treatment for 4-6 months, followed by slow withdrawal. The same length of $\mathrm{AD}$ is recommended by the Italian Guidelines for stroke management SPREAD (Stroke Prevention and Awareness Diffusion), but the power of this recommendation is weak (grade GPP, based on the clinical experience of the guideline development group, without research evidence) (SPREAD 2005).

\section{Conclusions}

Presently, there are still too many questions about PSD and too few answers. Crucial unresolved issues are essentially related to correct diagnostic and therapeutic approaches. There is clear evidence that an AD treatment may improve depression but it is unable to produce a full clinical remission or prevent the onset of diagnosable depressive illness. Moreover, data available regarding the choice or the length of optimal treatment are still not conclusive.

Because the benefits of AD therapy are potentially great, not only on mood but also on functional recovery, there is a pressing need for further research in this area of stroke medicine.

\section{References}

Aben I, Verhey F, Strik J, et al. 2003. A comparative study into the one year cumulative incidence of depression after stroke and myocardial infarction. J Neurol Neurosurg Psychiatry, 74:581-5. 
Alexopoulos GS. 2001. "The depression-executive dysfunction syndrome of late life": a specific target for D3 agonists? Am J Geriatr Psychiatry, 9:22-9.

Alexopoulos GS. 2006. The vascular depression hypothesis: 10 years later. Biol Psychiatry, 60:1304-5.

Alexopoulos GS, Meyers BS, Young RC, et al. 1997a. 'Vascular depression' hypothesis. Arch Gen Psychiatry, 54:915-22.

Alexopoulos GS, Meyers BS, Young RC, et al. 1997b. Clinically defined vascular depression. Am J Psychiatry, 154:562-5.

Almeida OP, Waterreus A, Hankey GJ. 2006. Preventing depression after stroke: Results from a randomized placebo-controlled trial. J Clin Psychiatry, 67:1104-9.

Andersen G, Vestergaard K, Lauritzen L. 1994a. Effective treatment of poststroke depression with the selective serotonin reuptake inhibitor citalopram. Stroke, 25:1099-104.

Andersen G, Vestergaard K, Riis J, et al. 1994b. Incidence of post-stroke depression during the first year in a large unselected stroke population determined using a valid standardized rating scale. Acta Psychiatr Scand, 90:190-5.

Anderson C, Hackett M, House A. 2004. Interventions for preventing depression after stroke. Cochrane Database Syst Rev, 2:CD003689.

Bak S, Tsiropoulos I, Kjaersgaard JO, et al. 2002. Selective serotonin reuptake inhibitors and the risk of stroke: a population-based case-control study. Stroke, 33:1465-73.

Bakish D. 2001. New standard of depression treatment: remission and full recovery. J Clin Psychiatry, 62(Suppl 26):5-9.

Berg A, Palomaki H, Lehtihalmes M, et al. 2001. Poststroke depression in acute phase after stroke. Cerebrovasc Dis, 12:14-20.

Bhogal SK, Teasell R, Foley N, et al. 2005. Heterocyclics and selective serotonin reuptake inhibitors in the treatment and prevention of poststroke depression. J Am Geriatr Soc, 53:1051-7.

Brodaty H, Withall A, Altendorf A, et al. 2007. Rates of depression at 3 and 15 months poststroke and their relationship with cognitive decline: the Sydney Stroke Study. Am J Geriatr Psychiatry, 15:477-86.

Carson AJ, MacHale S, Allen K, et al. 2000. Depression after stroke and lesion location: a systematic review. Lancet, 356:122-6.

Chemerinski E, Robinson RG, Kosier JT. 2001. Improved recovery in activities of daily living associated with remission of poststroke depression. Stroke, 32:113-17.

Chen Y, Guo JJ. 2006. Meta-analysis of antidepressant treatment for patients with poststroke depression. Stroke, 37:1365-6.

Chen Y, Patel NC, Guo JJ, et al. 2007. Antidepressant prophylaxis for poststroke depression: a meta-analysis. Int Clin Psychopharmacol, 22:159-66.

Choi-Kwon S, Han SW, Kwon SU, et al. 2006. Fluoxetine treatment in poststroke depression, emotional incontinence, and anger proneness: a double-blind, placebo-controlled study. Stroke, 37:156-61.

Dahmen N, Marx J, Hopf HC, et al. 1999. Therapy of early poststroke depression with venlafaxine: safety, tolerability, and efficacy as determined in an open, uncontrolled clinical trial. Stroke, 30:691-2.

Dam M, Tonin P, De Boni A, et al. 1996. Effects of fluoxetine and maprotiline on functional recovery in poststroke hemiplegic patients undergoing rehabilitation therapy. Stroke, 27:1211-14.

Damecour CL, Caplan D. 1991. The relationship of depression to symptomatology and lesion site in aphasic patients. Cortex, 27:385-401.

de Abajo FJ, Jick H, Derby L, et al. 2000. Intracranial haemorrhage and use of selective serotonin reuptake inhibitors. Br J Clin Pharmacol, 50:43-7.

Fedoroff JP, Robinson RG. 1989. Tricyclic antidepressants in the treatment of poststroke depression. J Clin Psychiatry, 50(Suppl):18-23.

Fedoroff JP, Starkstein SE, Parikh RM, et al. 1991. Are depressive symptoms nonspecific in patients with acute stroke?. Am J Psychiatry, 148:1172-6.

Fruehwald S, Gatterbauer E, Rehak P, et al. 2003. Early fluoxetine treatment of post-stroke depression A three-month double-blind placebocontrolled study with an open-label long-term follow up. J Neurol, 250:347-51.
Gainotti G, Antonucci G, Marra C, et al. 2001. Relation between depression after stroke, antidepressant therapy, and functional recovery. J Neurol Neurosurg Psychiatry, 71:258-61.

Gill D, Hatcher S. 1999. A systematic review of the treatment of depression with antidepressant drugs in patients who also have a physical illness. $J$ Psychosom Res, 47:131-43.

Gillen R, Tennen H, McKee TE, et al. 2001. Depressive symptoms and history of depression predict rehabilitation efficiency in stroke patients. Arch Phys Med Rehabil, 82:1645-9.

Gonzalez-Torrecillas JL, Mendlewicz J, Lobo A. 1995. Effects of early treatment of poststroke depression on neuropsychological rehabilitation. Int Psychogeriatr, 7:547-60.

Gordon WA, Hibbard MR. 1997. Poststroke depression: an examination of the literature. Arch Phys Med Rehabil, 78:658-63.

Gustafson Y, Nilsson I, Mattsson M, et al. 1995. Epidemiology and treatment of post-stroke depression. Drugs Aging, 7:298-309.

Hackett ML, Anderson CS, House AO. 2004. Interventions for treating depression after stroke. Cochrane Database Syst Rev, CD003437.

Hackett ML, Anderson CS, House AO. 2005a. Management of depression after stroke: a systematic review of pharmacological therapies. Stroke, 36:1098-103.

Hackett ML, Yapa C, Parag V, et al. 2005b. Frequency of depression after stroke: a systematic review of observational studies. Stroke, 36:1330-40.

Hemeryck A, Belpaire FM. 2002. Selective serotonin reuptake inhibitors and cytochrome P-450 mediated drug-drug interactions: an update. Curr Drug Metab, 3:13-37.

Herrmann N, Black SE, Lawrence J, et al. 1998. The Sunnybrook Stroke Study: a prospective study of depressive symptoms and functional outcome. Stroke, 29:618-24.

Hickie I, Scott E, Mitchell P, et al. 1995. Subcortical hyperintensities on magnetic resonance imaging: clinical correlates and prognostic significance in patients with severe depression. Biol Psychiatry, 37:151-60.

House A, Dennis M, Hawton K, et al. 1989. Methods of identifying mood disorders in stroke patients: experience in the Oxfordshire Community Stroke Project. Age Ageing, 18:371-9.

House A, Knapp P, Bamford J, et al. 2001. Mortality at 12 and 24 months after stroke may be associated with depressive symptoms at 1 month. Stroke, 32:696-701.

Jorge RE, Robinson RG, Arndt S, et al. 2003. Mortality and poststroke depression: a placebo-controlled trial of antidepressants. Am J Psychiatry, 160:1823-9.

Jorgensen L, Engstad T, Jacobsen BK. 2002. Higher incidence of falls in long-term stroke survivors than in population controls: depressive symptoms predict falls after stroke. Stroke, 33:542-7.

Kauhanen M, Korpelainen JT, Hiltunen P, et al. 1999. Poststroke depression correlates with cognitive impairment and neurological deficits. Stroke, 30:1875-80.

Kauhanen ML, Korpelainen JT, Hiltunen P, et al. 2000. Aphasia, depression, and non-verbal cognitive impairment in ischaemic stroke. Cerebrovasc Dis, 10:455-61.

Kellermann M, Fekete I, Gesztelyi R, et al. 1999. Screening for depressive symptoms in the acute phase of stroke. Gen Hosp Psychiatry, 21:116-21.

Kim P, Warren S, Madill H, et al. 1999. Quality of life of stroke survivors. Qual Life Res, 8:293-301.

King RB. 1996. Quality of life after stroke. Stroke, 27:1467-72.

Kneebone II, Dunmore E. 2000. Psychological management of post-stroke depression. Br J Clin Psychol, 39(Pt 1):53-65.

Kotila M, Numminen H, Waltimo O, et al. 1999. Post-stroke depression and functional recovery in a population-based stroke register. The Finnstroke study. Eur J Neurol, 6:309-12.

Laska AC, Martensson B, Kahan T, et al. 2007. Recognition of Depression in Aphasic Stroke Patients. Cerebrovasc Dis, 24:74-9.

Lauritzen L, Bendsen BB, Vilmar T, et al. 1994. Post-stroke depression: combined treatment with imipramine or desipramine and mianserin. A controlled clinical study. Psychopharmacology (Berl), 114:119-22. 
Lincoln NB, Flannaghan T. 2003. Cognitive behavioral psychotherapy for depression following stroke: a randomized controlled trial. Stroke, 34:111-15.

Lincoln NB, Flannaghan T, Sutcliffe L, et al. 1997. Evaluation of cognitive behavioural treatment for depression after stroke: a pilot study. Clin Rehabil, 11:114-22.

Linden T, Blomstrand C, Skoog I. 2007. Depressive disorders after 20 months in elderly stroke patients. A case-control study. Stroke, 38:1860-3.

Lipsey JR, Robinson RG. 1984. Nortriptyline for post-stroke depression. Lancet, 1:803.

Loubinoux I, Pariente J, Boulanouar K, et al. 2002. A single dose of the serotonin neurotransmission agonist paroxetine enhances motor output: Double-blind, placebo-controlled, fMRI study in healthy subjects. Neuroimage, 15:26-36.

Mast BT, MacNeill SE, Lichtenberg PA. 2004. Post-stroke and clinicallydefined vascular depression in geriatric rehabilitation patients. Am J Geriatr Psychiatry, 12:84-92.

Maurer-Spurej E, Pittendreigh C, Solomons K. 2004. The influence of selective serotonin reuptake inhibitors on human platelet serotonin. Thromb Haemost, 91:119-28.

Miyai I, Reding MJ. 1998. Effects of antidepressants on functional recovery following stroke: a double-blind study. J Neuro Rehab, 12:5-13.

Morris PL, Robinson RG, Andrzejewski P, et al. 1993. Association of depression with 10-year poststroke mortality. Am J Psychiatry, 150:124-9.

Murray V, von Arbin M, Bartfai A, et al. 2005. Double-blind comparison of sertraline and placebo in stroke patients with minor depression and less severe major depression. J Clin Psychiatry, 66:708-16.

Neau JP, Ingrand P, Mouille-Brachet C, et al. 1998. Functional recovery and social outcome after cerebral infarction in young adults. Cerebrovasc Dis, 8:296-302.

Paolucci S, Antonucci G, Grasso MG, et al. 2001. Post-stroke depression, antidepressant treatment and rehabilitation results. A case-control study. Cerebrovasc Dis, 12:264-71.

Paolucci S, Antonucci G, Pratesi L, et al. 1999. Poststroke depression and its role in rehabilitation of inpatients. Arch Phys Med Rehabil, 80:985-90.

Paolucci S, Gandolfo C, Provinciali L, et al. on behalf of DESTRO Study Group. 2006. The Italian multicenter observational study on post-stroke depression (DESTRO). J Neurol, 253:556-62.

Pariente J, Loubinoux I, Carel C, et al. 2001. Fluoxetine modulates motor performance and cerebral activation of patients recovering from stroke. Ann Neurol, 50:718-29.

Pohjasvaara T, Vataja R, Leppavuori A, et al. 2001. Depression is an independent predictor of poor long-term functional outcome post-stroke. Eur J Neurol, 8:315-19.

Ramasubbu R. 2004. Cerebrovascular effects of selective serotonin reuptake inhibitors: a systematic review. J Clin Psychiatry, 65:1642-53.

Ramasubbu R, Robinson RG, Flint AJ, et al. 1998. Functional impairment associated with acute poststroke depression: the Stroke Data Bank Study. J Neuropsychiatry Clin Neurosci, 10:26-33.

Rampello L, Chiechio S, Nicoletti G, et al. 2004. Prediction of the response to citalopram and reboxetine in post-stroke depressed patients. Psychopharmacology (Berl), 173:73-8.

Reding MJ, Orto LA, Winter SW, et al. 1986. Antidepressant therapy after stroke. A double-blind trial. Arch Neurol, 43:763-5.
Robinson RG, Schultz SK, Castillo C, et al. 2000. Nortriptyline versus fluoxetine in the treatment of depression and in short-term recovery after stroke: a placebo-controlled, double-blind study. Am J Psychiatry, 157:351-9.

Sarti C, Rastenyte D, Cepaitis Z, et al. 2000. International trends in mortality from stroke, 1968 to 1994. Stroke, 31:1588-601.

Schubert DS, Taylor C, Lee S, et al. 1992. Detection of depression in the stroke patient. Psychosomatics, 33:290-4.

Schulz R, Beach SR, Ives DG, et al. 2000. Association between depression and mortality in older adults: the Cardiovascular Health Study. Arch Intern Med, 160:1761-8.

Schwartz JA, Speed NM, Brunberg JA, et al. 1993. Depression in stroke rehabilitation. Biol Psychiatry, 33:694-9.

Simpson S, Baldwin RC, Jackson A, et al. 1998. Is subcortical disease associated with a poor response to antidepressants? Neurological, neuropsychological and neuroradiological findings in late-life depression. Psychol Med, 28:1015-26.

Sinyor D, Amato P, Kaloupek DG, et al. 1986. Post-stroke depression: relationships to functional impairment, coping strategies, and rehabilitation outcome. Stroke, 17:1102-7.

Skop BP, Brown TM. 1996. Potential vascular and bleeding complications of treatment with selective serotonin reuptake inhibitors. Psychosomatics, 37:12-6.

[SPREAD] Stroke Prevention and Educational Awareness Diffusion. 2005. Complicanze psico-cognitive dell'ictus. In Ictus cerebrale: linee guida italiane di prevenzione e trattamento.Milano: Pubblicazioni Catel - Hyperphar Group SpAp 435-79.

Taylor WD, Steffens DC, Krishnan KR. 2006. Psychiatric disease in the twenty-first century: The case for subcortical ischemic depression. Biol Psychiatry, 60:1299-303.

Townend BS, Whyte S, Desborough T, et al. 2007. Longitudinal prevalence and determinants of early mood disorder post-stroke. J Clin Neurosci, 14:429-34.

Turner-Stokes L, Hassan N. 2002. Depression after stroke: a review of the evidence base to inform the development of an integrated care pathway. Part 2: Treatment alternatives. Clin Rehabil, 16:248-60.

van de Weg FB, Kuik DJ, Lankhorst GJ. 1999. Post-stroke depression and functional outcome: a cohort study investigating the influence of depression on functional recovery from stroke. Clin Rehabil, 13:268-72.

Van de MH, Geurts AC, Van Limbeek J. 2003. Pharmacologic treatment of poststroke depression: a systematic review of the literature. Top Stroke Rehabil, 10:79-92.

Vataja R, Leppavuori A, Pohjasvaara T, et al. 2004. Poststroke depression and lesion location revisited. J Neuropsychiatry Clin Neurosci, 16:156-62.

Verdelho A, Henon H, Lebert F, et al. 2004. Depressive symptoms after stroke and relationship with dementia: A three-year follow-up study. Neurology, 62:905-11.

Wiart L, Petit H, Joseph PA, et al. 2000. Fluoxetine in early poststroke depression: a double-blind placebo-controlled study. Stroke, 31:1829-32.

Williams LS, Ghose SS, Swindle RW. 2004. Depression and other mental health diagnoses increase mortality risk after ischemic stroke. Am J Psychiatry, 161:1090-5.

Windle V, Corbett D. 2005. Fluoxetine and recovery of motor function after focal ischemia in rats. Brain Res, 1044:25-32.

Yamakawa Y, Satoh S, Sawa S, et al. 2005. Efficacy of milnacipran on poststroke depression on inpatient rehabilitation. Psychiatry Clin Neurosci, 59:705-10. 